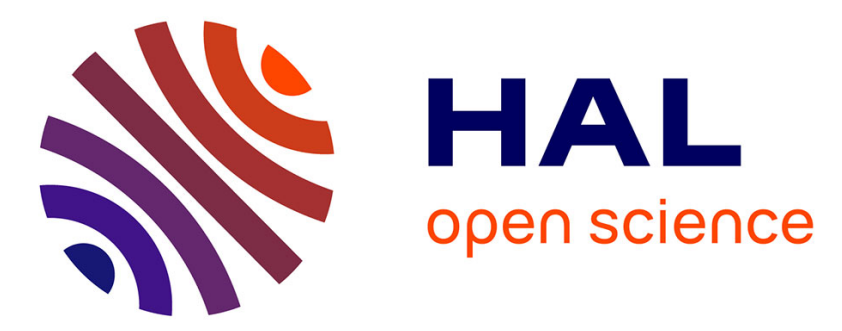

\title{
Early word segmentation in infants acquiring Parisian French: task-dependent and dialect-specific aspects
}

Thierry Nazzi, Karima Mersad, Megha Sundara, Galina Iakimova, Linda Polka

\section{- To cite this version:}

Thierry Nazzi, Karima Mersad, Megha Sundara, Galina Iakimova, Linda Polka. Early word segmentation in infants acquiring Parisian French: task-dependent and dialect-specific aspects. Journal of Child Language, 2014, 41 (3), pp.600-633. 10.1017/S0305000913000111 . hal-03131303

\section{HAL Id: hal-03131303 https://hal.science/hal-03131303}

Submitted on 4 Feb 2021

HAL is a multi-disciplinary open access archive for the deposit and dissemination of scientific research documents, whether they are published or not. The documents may come from teaching and research institutions in France or abroad, or from public or private research centers.
L'archive ouverte pluridisciplinaire HAL, est destinée au dépôt et à la diffusion de documents scientifiques de niveau recherche, publiés ou non, émanant des établissements d'enseignement et de recherche français ou étrangers, des laboratoires publics ou privés. 


\title{
Early word segmentation in infants acquiring Parisian French: task-dependent and dialect-specific aspects*
}

THIERRY NAZZ I

Université Paris Descartes, Sorbonne Paris Cité, Paris, France and CNRS, Laboratoire Psychologie de la Perception, Paris, France

KARIMA MERSAD

Université Paris Descartes, Sorbonne Paris Cité, Paris, France

MEGHA SUNDARA

Department of Linguistics, University of California, Los Angeles, CA

$$
\text { GALINA IAKIMOVA }
$$

Université Paris Descartes, Sorbonne Paris Cité, Paris, France

A ND

\author{
LINDA POLKA
}

School of Communication Sciences $\&$ Disorders, McGill University

\begin{abstract}
(Received 5 April $20 \mathrm{I} 2$-Revised 24 Fuly $20 \mathrm{I} 2$-Accepted 7 Fanuary 2013-
First published online го May 2013)
\end{abstract}

\section{A B S TRACT}

Six experiments explored Parisian French-learning infants' ability to segment bisyllabic words from fluent speech. The first goal was to assess whether bisyllabic word segmentation emerges later in infants acquiring European French compared to other languages. The second goal was to determine whether infants learning different dialects of the same language have partly different segmentation abilities, and whether segmenting a non-native dialect has a cost. Infants were tested on standard European or Canadian French stimuli, in the word-passage or

[*] This study was conducted with the support of an ANR grant \# o7-BLAN-oor4-or to TN and a grant from the Social Sciences \& Humanities Research Council of Canada to LP. Special thanks to the infants and their parents for their kindness and cooperation, Léo-Lyuki Nishibayashi for help with the testing, and James White for carefully proofreading the manuscript. Address for correspondence: Thierry Nazzi, Laboratoire Psychologie de la Perception, Institut Pluridisciplinaire des Saints Pères, 45 rue des Sts Pères, 75006 Paris, France. tel: $+33 \cdot 1 \cdot 42 \cdot 86 \cdot 43 \cdot 15$; fax: $+33 \cdot 1 \cdot 42 \cdot 86 \cdot 33 \cdot 22$. e-mail: thierry.nazzi@parisdescartes.fr 
passage-word order. Our study first establishes an early onset of segmentation abilities: Parisian infants segment bisyllabic words at age $0 ; 8$ in the passage-word order only (revealing a robust order of presentation effect). Second, it shows that there are differences in segmentation abilities across Parisian and Canadian French infants, and that there is a cost for cross-dialect segmentation for Parisian infants. We discuss the implications of these findings for understanding word segmentation processes.

\section{INTRODUCTION}

For infants, developing a lexicon involves three abilities: the ability to extract and store word forms, the ability to build concepts for the objects and events in the world, and finally the ability to appropriately link word forms and concepts. The present study focuses on the first ability, namely the capacity to extract the sound pattern of words from fluent speech (henceforward, word form segmentation). Word form segmentation constitutes a crucial step in speech processing, which allows infants and adults to determine the lexical units that constitute the utterances they hear. The ability to extract word forms from spoken language is thought to play a critical role for the acquisition of the lexicon. Supporting this claim, links have been observed between word segmentation performance and later vocabulary levels (Newman, Bernstein Ratner, Jusczyk, Jusczyk \& Dow, 2006), and newly segmented words have been shown to be easier to associate to new objects at age I ; (Graf Estes, Evans, Alibali \& Saffran, 2007). In this study, we investigate early word segmentation by Parisian French-learning infants, focusing on bisyllabic words. In the current literature, this skill becomes evident (using natural samples of speech) by I; 4 for infants acquiring Parisian French (Nazzi, Iakimova, Bertoncini, Frédonie \& Alcantara, 2006) and by 0;8 for infants acquiring Canadian French (Polka \& Sundara, 2012). A principled understanding of these differences requires a closer examination of dialect- and task-related factors that potentially influence how word segmentation skills emerge in infants. As a first step, Experiments $\mathrm{I}-3$ reassess segmentation of bisyllabic words by Parisian infants using the stimuli used by Polka and Sundara (2012). Experiments 4-6 then explore potential cross-dialect differences in this emerging skill. Both issues are further discussed in Sections $\mathrm{I}$ and 2 below.

If word form segmentation is a crucial skill, it is far from a trivial accomplishment, since word boundaries are acoustically not clearly marked, and less than $10 \%$ of the words directed to infants are presented in isolation (Brent \& Siskind, 200I; van de Weijer, I998). Given that infants start learning words before $\mathrm{I} ; \circ$, it is important to evaluate speech segmentation abilities prior to that age to determine when infants start segmenting word 
forms, the kind of cues they use, the kind of lexical structures (monosyllabic words, multisyllabic words) they can segment at different ages, and whether segmentation skills emerge at the same age and rely on the same cues across languages.

At present, the ability to extract word forms from natural speech utterances has been found to emerge between $0 ; 6$ and $\mathrm{I} \cdot 0$ in multiple languages: English (e.g., Jusczyk \& Aslin, I995; Saffran, Aslin \& Newport, I996), Parisian French (Goyet, de Schonen \& Nazzi, 20ı ; Mersad \& Nazzi, 20 I 2; Nazzi et al., 2006), Canadian French (Marquis \& Shi, 2008; Polka \& Sundara, 20ı 2; Shi \& Lepage, 2008), Dutch (Houston, Jusczyk, Kuijpers, Coolen \& Cutler, 2000; Johnson \& Tyler, 20ıо; Kooijman, Hagoort \& Cutler, 2005, 2009), and German (Höhle \& Weissenborn, 2003). During this period, infants exploit various cues present in the speech signal, including transitional probabilities between syllables (TPs; Johnson \& Jusczyk, 200ı; Mersad \& Nazzi, 20ı 2; Saffran et al., ı996; Thiessen \& Saffran, 2003), the rhythmic unit of the native language (Curtin, Mintz \& Christiansen, 2005; Goyet et al., 2010; Goyet, Nishibayashi \& Nazzi, unpublished observations; Jusczyk, Houston \& Newsome r 999; Nazzi et al., 2006), prosodic boundaries (Gout, Christophe \& Morgan, 2004; Seidl \& Johnson, 2006), coarticulatory cues (Johnson \& Jusczyk, 200I), allophonic information (Jusczyk, Hohne \& Bauman, I999; Mattys \& Jusczyk, 200ıa), phonotactic information (Gonzalez Gomez \& Nazzi, in press; Mattys \& Jusczyk, 200Ib; Mattys, Jusczyk, Luce \& Morgan, I999), and possibly pitch accent (Nazzi, Dilley, Jusczyk, Shattuck-Hufnagel \& Jusczyk, 2005). The first two factors (TPs and rhythmic units) have received the most attention, and have been proposed to be crucial when word segmentation emerges (Jusczyk et al., I999b; Nazzi et al., 2006; Saffran et al., I996). While TPs are taken to be language-general, rhythmic units differ across classes of languages, and the combined use of both cues have been proposed to account for early differences in segmentation abilities across languages, in particular between English-learners relying on trochaic units and Frenchlearners relying on syllabic units (Nazzi et al., 2006; Polka \& Sundara, 20I2). We will return to this issue in the 'General discussion', in relation to the new evidence of French-learning infants' early segmentation abilities provided in the present study.

Evidence for infant speech segmentation abilities emerges from two types of studies. One type, following Jusczyk and Aslin (I995), uses natural language stimuli in which infants are tested on their ability to extract and recognize target words that are embedded in complex natural passages. This is done either by familiarizing infants with isolated target words and then presenting them with passages with and without the target words or, vice versa, by familiarizing them with passages containing target words and then presenting them with the isolated target words and some control words. 
These testing situations are relatively close to infants' natural environment, offering infants various segmentation cues, but they have the disadvantage that the number of cues that are present and their relative strengths are not experimentally controlled. The other type, following Saffran et al. ( 1996), relies on artificial language materials constructed to examine specific aspects of language processing. Artificial language materials are simpler and less variable than natural language stimuli (they typically contain four 'words'), with the advantage that they can be more controlled in terms of the cues present. In these studies, infants are first familiarized with a continuous speech stream in which four words (i.e., sequences of co-occurring syllables) are repeated in random order, and then tested on their recognition of the words compared to 'part-words' (i.e., sequences of syllables that are equally frequent in the artificial language, but that cross a word boundary).

Although word segmentation abilities first emerge between $0 ; 6$ and $\mathrm{i} ; 0$ cross-linguistically, evidence of early segmentation abilities has been more difficult to obtain from Parisian French infants under certain conditions. When Parisian infants have been tested in artificial language experiments, they succeeded at an early age. In these studies using simple artificial languages in which all the words had the same number of syllables, and in which segmentation can only be performed using information related to the transitional probabilities between adjacent syllables, Parisian French infants segmented trisyllabic words at the youngest age tested, that is $0 ; 8$ (Mersad \& Nazzi, 2012). This age is close to when TP segmentation is attested in English (0;7: Saffran et al., I996; Thiessen \& Saffran, 2003) and Dutch (o; 5 : Johnson \& Tyler, 2010). However, a different picture emerges from studies using natural language stimuli. While Parisian French-learners segmented monosyllabic words (Gout, 200I) by o;8, Nazzi et al. (2006) failed to find evidence of bisyllabic segmentation before I; 4 . In contrast, English-learning infants segmented both monosyllabic and trochaic bisyllabic words at o; 7, and iambic bisyllabic words at o; г (Jusczyk \& Aslin, I995; Jusczyk et al., I999b).

One explanation for these findings is that the ability to segment word forms emerges later in development when infants are acquiring French, and that this difference is highlighted when using natural stimuli that contain many words and a lot of variability. However, this explanation fails to explain recent findings by Polka and Sundara (2012). In this study, Canadian French-learners were tested on their ability to segment bisyllabic words in French using natural speech stimuli at $0 ; 8$. The procedure used was similar to Nazzi et al. (2006), infants being familiarized with repetitions of two bisyllabic words, and then tested on four different passages, two corresponding to the familiarized/target words, and two corresponding to new/control words. Infants at test listened longer to the passages with the target words, establishing that they had recognized the bisyllabic words. 
This finding was obtained in two separate experiments, one using Canadian French stimuli, and one using standard European French stimuli. These results establish that word segmentation skills do not emerge later in infants acquiring French, since these skills are evident at the same age in infants learning Canadian French (Polka \& Sundara, 20I2) and in infants learning Canadian or American English (respectively: Polka \& Sundara, 2012; Jusczyk et al., I 999b). These findings raise again the issue of why Parisian French infants failed to segment bisyllabic words from fluent speech at o;8 in Nazzi et al. (2006).

The present study focused on bisyllabic word segmentation, since it is with this kind of words that important differences in results were found between the Parisian (Nazzi et al., 2006) and Canadian (Polka \& Sundara, 2012) French infants. Exploring bisyllabic word segmentation also bears on a discussion about the kind of cues that may be used for their segmentation (prosodic, TPs) and the mechanisms that are implicated in their segmentation. The present study includes six experiments conducted to address two main goals.

\section{Reassessing word segmentation in Parisian French-learners at o;8: task-dependent effects?}

The first goal (addressed in Experiments $\mathrm{I}-3$ ) was to reassess bisyllabic word segmentation in Parisian French-learners at o; 8. This was motivated by the fact that although Nazzi et al. (2006) and Polka and Sundara (2012) used very similar methodologies, there were two important methodological differences that may have facilitated segmentation in Polka and Sundara (2012). The first one is that the Nazzi et al. (2006) stimuli were less infant-directed in that they were produced with a faster speech rate, lower pitch, and smaller pitch excursions (more details below) than both the Canadian French and standard European French stimuli used by Polka and Sundara (2012). Given evidence from the artificial language paradigm that infant-directed speech elicits segmentation earlier in development than adult-directed speech ('Thiessen, Hill \& Saffran, 2005), it is possible that Canadian infants outperformed Parisian infants because they were tested on stimuli that were easier to segment. A second methodological difference pertains to the duration of the familiarization phase, which was shorter in Nazzi et al. (2006) than in Polka and Sundara (2012): 20 versus 30 s respectively. While the shorter familiarization time in Nazzi et al. (2006) was chosen to offset the faster speech rate at which their stimuli were produced, essentially to equate the number of tokens heard during familiarization with previous studies on English (e.g., Jusczyk et al., I 999b), it might be that this did not give Parisian infants enough time to reliably process and encode the target words. Experiment I was designed to address the contribution of 
these factors to the age differences observed in studies of word segmentation of French-learning infants.

Related to this first goal, we also tested Parisian infants in the passage-word order. In previous research using natural speech, Parisian and Canadian French-learning infants have only been tested using a word-passage order, in which infants are familiarized with repetitions of two isolated words and then tested on passages with or without these target words. However, previous studies on English have used both the word-passage and the passage-word order, in which infants are familiarized with passages containing two target words and are then tested on repetitions of these target words in isolation (e.g., Jusczyk \& Aslin, I 995; Jusczyk et al., I999b). In all cases in which English-learning infants were tested in both orders, they could segment in both conditions. We implemented the passage-word order because it is more analogous to the artificial language learning studies and might allow infants more time to compute and use TP cues related to word boundaries. Also, the task demands in that order are more similar to the Mersad and Nazzi (2012) study that showed successful multisyllabic word segmentation in Parisian French-learners at $0 ; 8$ using an artificial language paradigm. Experiments 2 and 3 were conducted to evaluate bisyllabic word segmentation in the passage-word order.

\section{Exploring the potential impact of dialect differences on early segmentation abilities}

The second goal (addressed in Experiments 4-6) was to explore whether hearing different dialects of French might have led Parisian and Canadian French infants to develop (slightly) different, i.e., dialect-specific, segmentation procedures. This outcome would support an alternative explanation for the differences between the Nazzi et al. (2006) and Polka and Sundara (2012) findings as opposed to the more methodological explanation explored in Experiments $\mathrm{I}-3$. Such processing differences could be grounded in the fact that French dialects of France and Canada differ at both the prosodic and the phonetic levels. Canadian French includes a greater degree of variation in vowel production in comparison to standard European French. For example, in Canadian French, vowels are often produced with diphthongization and lax vowels occur allophonically (Picard, I987), two forms of vowel variation that are not found in standard European French. Additionally, Canadian French has more variable intonation patterns compared to standard European French at the sentence level, and these differences have been shown to support identification of these regional dialects by Francophone adults without phonetics training (Menard, Ouellon \& Dolbec, I 999). Moreover, an analysis of the stimuli used in the present study also suggests differences in prosodic marking at the word level 
between the two dialects (see details below). Such dialectal differences in the acoustic instantiation of prosody at the sentence and word level are likely to impact segmentation, as will be further discussed in the 'General discussion').

Note also that our interest in starting to explore cross-dialect word segmentation is motivated not only by the fact that the studies of Nazzi et al. (2006) and Polka and Sundara (2012) suggest such dialectal differences (which will be reassessed in the present Experiments $\mathrm{I}-3$ ), but also by other recent findings directly exploring dialect perception in infancy. For example, English-learning infants can discriminate their native dialect from another dialect of their native language around o; 5 (Butler, Floccia, Goslin \& Panneton, 20I I ; Nazzi, Jusczyk \& Johnson, 2000). Importantly, dialectal differences appear to influence known word recognition in English-learners at I ; 3 (Best, Tyler, Gooding, Orlando \& Quann, 2009). Moreover, impact of dialect variability on speech segmentation was demonstrated in a recent study by Schmale, Cristia, Seidl, and Johnson (2010). They familiarized English-learning infants with words spoken in one dialect (their own North Midland American dialect, or a different Southern Ontario Canadian dialect), and then tested them with passages produced in the other dialect. While infants aged $\mathbf{I} ; 0$ succeeded at recognizing the words across dialects, infants aged $0 ; 9$ (an age close to the age of $0 ; 8$ used in the present study) could not, suggesting that cross-dialect differences impeded recognition. However, because Schmale et al. (2010) tested only infants learning one dialect, their findings cannot address the questions of whether segmentation abilities might develop differently for infants acquiring different dialects of the same language, nor whether dialect adaptation might present different challenges depending on one's own native dialect. Finally, in Schmale et al. (2010), the dialect was switched within the segmentation task, so it remains unclear whether infants failed to segment or whether they failed to map the corresponding words in the two dialects. Such differences may be important in understanding the current discrepancies in word segmentation reported for infants acquiring French in Paris and in Canada. The present study will go a step further in evaluating the possibility of cross-dialect differences in segmentation abilities. Therefore, following Experiments $\mathrm{I}-3$, in which early bisyllabic word segmentation is reevaluated in Parisian French-learning infants, Experiments 4-6 will evaluate dialect effects. Table I provides a description of each experiment along with a summary of the results.

\section{EXPERIMENT I}

As a first step towards understanding the discrepancies in word segmentation studies of French-learning infants conducted in Canada and in France, we tested Parisian French-learning infants using the standard 
TABLE I. Summary of all experimental conditions and segmentation results. Parisian French-learning infants were tested in all conditions

\begin{tabular}{|c|c|c|c|c|c|c|c|}
\hline & $\begin{array}{c}\text { Age } \\
\text { (months) }\end{array}$ & stimuli & $\begin{array}{c}\text { test order } \\
\text { familarization/ } \\
\text { test }\end{array}$ & $\begin{array}{c}\text { familiarization } \\
\text { duration (s) }\end{array}$ & $\begin{array}{c}\# \\
\text { participants }\end{array}$ & $\begin{array}{c}\text { result } \\
p \text {-value }\end{array}$ & $\eta_{\mathrm{p}}^{2}$ \\
\hline \multicolumn{8}{|c|}{ - Revisiting bisyllabic word segmentation in Parisian French-learning infants } \\
\hline \multirow[t]{3}{*}{ Exp. I } & 8 & European French & word/passage & 30 & I 6 & n.s. & $\cdot 00 \mathrm{I}$ \\
\hline & 12 & European French & word/passage & 30 & I 6 & n.s. & .094 \\
\hline & I 6 & European French & word/passage & 30 & I 6 & $p<\cdot \circ \circ \mathrm{I}$ & 549 (large) \\
\hline Exp. 3 & 8 & European French & passage/final syllable & 30 & 24 & n.s. & .005 \\
\hline \multicolumn{8}{|c|}{ - Cross-dialect segmentation } \\
\hline Exp. 4 & 8 & Canadian French & word/passage & 30 & I 6 & n.s. & .065 \\
\hline Exp. 5 & 8 & Canadian French & passage/word & 30 & 24 & n.s. & $\cdot . ০ ০$ \\
\hline Exp. 6 & 8 & Canadian French & passage/word & 45 & I6 & $p=.030$ & $.280($ medium $)$ \\
\hline
\end{tabular}


European French stimuli/recordings of Polka and Sundara (2012), which were produced in a more infant-directed register than the French stimuli used by Nazzi et al. (2006). Indeed, our analyses of the speech passages used in each study show that the standard European French stimuli used by Polka and Sundara (2012) had a slower speech rate $(4 \cdot 3$ versus $5 \cdot 2$ syllables/ second), higher mean Fo (253 versus $204 \mathrm{~Hz}$ ) and wider pitch incursions (Fo range of 273 versus $193 \mathrm{~Hz}$ ) than the Nazzi et al. (2006) stimuli, which are all characteristics of infant-directed speech (Fernald \& Simon, I984; Papousek, Papousek \& Haekel, i 987).

Moreover, we also used the same testing procedure as Polka and Sundara (2012), with a slightly longer exposure to the isolated words in the familiarization phase compared to the Nazzi et al. (2006) study. Parisian infants (aged $\circ ; 8$, I; $\circ$, or $\mathrm{I} ; 4$ ), were familiarized for $30 \mathrm{~s}$ with repetitions of two target words presented in isolation, and then tested with passages with or without those target words.

The rationale was that if the later emergence of bisyllabic segmentation previously reported for Parisian infants is due to differences in the specific test procedures and/or indexical properties of the speech stimuli, then Parisian infants should succeed at $0 ; 8$ when tested with the Polka and Sundara (2012) stimuli. Alternatively, if the age differences previously observed are not due to these stimulus or procedural factors, then the Parisian infants should again fail to segment the bisyllabic words before $\mathrm{I} ; 4$.

\section{METHOD}

\section{Participants}

Forty-eight infants from French-speaking families living in the Paris area were tested: sixteen aged $\circ ; 8(M=0 ; 8 \cdot 13$; range: $0 ; 7 \cdot 27-0 ; 8 \cdot 28 ; 9$ girls,

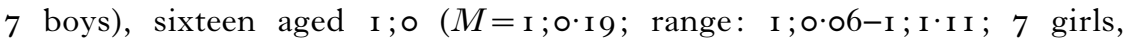
9 boys), and sixteen aged I;4 ( $M=\mathrm{I} ; 4^{\cdot}$ I 7 ; range: I;3.29-I;5. I I ; 8 girls, 8 boys). At o; 8 , twelve additional infants were tested but their data were excluded from the analyses: seven for fussiness/crying, five infants for having at least three orientation times in the test phase shorter than $3 \mathrm{~s}$ (criterion used to ensure that infants heard at least one sentence/word per trial). The data of six infants aged I ; o and four infants aged I ; 4 were also excluded for fussiness or crying.

\section{Stimuli}

The stimuli and recordings were those used in Experiment 4 of Polka and Sundara (2012). All recordings were made in a sound-attenuated booth by a female talker (from Lyon, France) who was a native speaker of standard European French, which is the same dialect as the one spoken in Paris. 
TABLE 2. Acoustic analysis of the first and second syllable of target words in European and Canadian French (stimuli recorded by Polka $\xi^{\circ}$ Sundara, 2012)

\begin{tabular}{|c|c|c|c|c|}
\hline \multirow[b]{2}{*}{ MEASURES } & \multicolumn{2}{|c|}{ European French } & \multicolumn{2}{|c|}{ Canadian French } \\
\hline & Syllable I & Syllable 2 & Syllable I & Syllable 2 \\
\hline \multicolumn{5}{|l|}{ Passage words } \\
\hline Duration (ms) & I 52 & $280 * *$ & 223 & $355^{* * *}$ \\
\hline Amplitude $(\mathrm{dB})$ & $69 \cdot 3$ & $65 \cdot 2 * *$ & $72 \cdot 8$ & $72 \cdot \mathrm{I}$ \\
\hline Pitch $(\mathrm{Hz})$ & 230 & 247 & $23 I$ & 243 \\
\hline \multicolumn{5}{|l|}{ List words } \\
\hline Duration (ms) & I 43 & $387^{* * *}$ & 259 & 5 I $5 * *$ \\
\hline Amplitude $(\mathrm{dB})$ & $76 \cdot 5$ & $7 \mathrm{I} \cdot 4^{* * *}$ & $72 \cdot 8$ & $75^{*}$ \\
\hline Pitch $(\mathrm{Hz})$ & 243 & $25 \mathrm{I}$ & 234 & $256^{*}$ \\
\hline
\end{tabular}

NOTES: Statistical differences between the two syllables: ${ }^{*} p<\cdot 05 ;{ }^{* * *} p<\cdot 00 \mathrm{I}$.

She first recorded four 6-sentence passages, one passage for each of the four target bisyllabic nouns: béret (English: beret), surprise (English: surprise), guitare (English: guitar), and devis (English: invoice). Each noun appeared in every sentence of its appropriate passage. The specific text for each passage is reported in Polka and Sundara (2012). The speaker was asked to pronounce the stimuli as if speaking to an infant. The passages were on average $\mathrm{I} 8.4 \mathrm{~s}$ long. The target bisyllabic words produced within the passages had an average duration of $432 \mathrm{~ms}$ (béret: $37 \mathrm{I} \mathrm{ms}$; surprise: $546 \mathrm{~ms}$; guitare: $449 \mathrm{~ms}$; devis: $36 \mathrm{I} \mathrm{ms).}$

For each word, the same speaker also produced with some variation a list of thirteen to seventeen isolated occurrences for use in the familiarization phase. The average duration of the lists was $20.6 \mathrm{~s}(S D=0.6)$. The target bisyllabic words spoken in isolation had an average duration of $530 \mathrm{~ms}$ (béret: $409 \mathrm{~ms}$; surprise: $7 \mathrm{I} 5 \mathrm{~ms}$; guitare: $605 \mathrm{~ms}$; devis: 44I ms; average pause duration $700 \mathrm{~ms}$ ).

Acoustic correlates of stress (duration, amplitude, Fo) for the isolated target words and for the target words within passages are reported in Polka and Sundara (2012). The values for the European French stimuli are summarized in Table 2 (left columns). In passages, the second syllables of these bisyllabic words were significantly longer $(t(23)=4 \cdot 6, p<\cdot \circ \circ \mathrm{I}$, $d=\mathbf{I} \cdot 38)$ and had a lower intensity than the first syllable $(t(23)=-5 \cdot 20$, $p<\cdot 000 \mathrm{I}, d=0.66)$; the mean Fo between the two syllables was not significantly different $(t(23)=\mathbf{I} \cdot 2, p=\cdot 23)$. Similarly for list words, the second syllables of these bisyllabic words were significantly longer $\left(t{ }_{59}\right)=-\mathrm{I}_{3} \cdot \mathbf{5}$, $p<\cdot .00 \mathrm{I}, d=24.4)$ and had a lower intensity $\left(t(59)=-\mathrm{IO}_{\mathrm{I}} \mathrm{I}, p<\cdot 000 \mathrm{I}\right.$, $d=-0.94)$ than their first syllables; again there were no differences between the two syllables on mean Fo $(t(59)=-0 \cdot 8, p=\cdot 42)$. 


\section{Procedure and apparatus}

All experiments were conducted inside a sound-attenuated room, in a three-sided test booth made of pegboard panels (bottom part) and a white curtain (top part). The test booth had a red light and a loudspeaker (SONY xs-Fi 722) mounted at eye level on each of the side panels and a green light mounted on the center panel. Directly below the center light a 5-cm hole accommodated a video camera used to monitor each session.

A (Dell Optiplex) computer, a TV screen connected to the camera, and a response box were located outside the sound-attenuated room. The response box, which was connected to the computer, was equipped with a series of buttons. The box was controlled by the observer, who looked at the video of the infant on the TV screen and pressed the buttons of the response box according to the direction of the infant's head, thus starting and stopping the flashing of the lights and the presentation of the sounds. The observer, and the infant's caregiver, wore earplugs and listened to masking music over tight-fitting headphones, which prevented them from hearing the stimuli presented. Information about the direction and duration of the head-turn and the total trial duration were stored in a file on the computer.

The version of the Headturn Preference Procedure (HPP) used followed Jusczyk and Aslin (I995). Infants were held on their caregiver's lap. The caregiver was seated in a chair in the center of the test booth. Each trial began with the green light on the center panel blinking until the infant had oriented in that direction. Then, the center light was extinguished and the red light above the loudspeaker on one of the side panels began to flash. When the infant made a turn of at least $30^{\circ}$ in the direction of the loudspeaker, the stimulus for that trial began to play. Each stimulus was played to completion (i.e., when all the word repetitions or the six sentences had been presented) or stopped immediately after the infant failed to maintain the $30^{\circ}$ headturn for 2 consecutive seconds ( $200 \mathrm{~ms}$ fade-out). The stimuli were stored in digitized form on the computer, and were delivered by the loudspeakers via an audio amplifier (Marantz $\mathrm{PM}_{4000}$ ). If the infant turned away from the target by $30^{\circ}$ in any direction for less than $2 \mathrm{~s}$ and then turned back again, the trial continued but the time spent looking away was not included in the orientation time. The flashing red light remained on for the entire duration of the trial.

Each experimental session began with a familiarization phase in which infants heard repetitions of two of the target words on alternating trials until they accumulated at least $30 \mathrm{~s}$ of orientation times to each (since familiarization time is only evaluated at the end of a trial, infants always heard the familiarization stimuli for more than $30 \mathrm{~s}$; see 'Results and discussion'). The side of the loudspeaker from which the stimuli were presented was randomly varied from trial to trial. 
The test phase began immediately after the familiarization criterion was attained. It consisted of three test blocks at age $0 ; 8$, and two test blocks at ages $\mathrm{I} ; O$ and I ; 4 . The order of presentation of the four different passages within each block was randomized. Half of the passages corresponding to the familiarized nouns were presented to the right side, the other half to the left side. The same was done for the control nouns.

\section{Design}

In each age group, half of the infants were familiarized with the nouns beret and surprise, and the other half with the nouns devis and guitare.

\section{RESULTS AND DISCUSSION}

\section{Familiarization phase}

For all three age groups, mean orientation times during familiarization were calculated for the infants in both familiarization conditions. A 2-way ANOVA with the between-subject factors of age $(0 ; 8,1 ; 0$, and I;4) and familiarization condition (familiarization with béret-surprise versus devisguitare) was conducted. The effect of age was significant $(F(2,42)=7 \cdot 75$, $\left.p=\cdot \circ \circ \mathrm{I}, \eta_{p}^{2}=\cdot 270\right)$, due to longer familiarization times at $\circ ; 8(M=42 \cdot \mathrm{I} \mathrm{s})$ and $\mathrm{I} ; \circ(M=44.5 \mathrm{~s})$ compared to $\mathrm{I} ; 4(M=35 \cdot 0 \mathrm{~s})$. However, there was no effect of condition $(F(\mathrm{I}, 42)=\mathrm{I} \cdot 52, p=\cdot 22)$, and no age $\times$ condition interaction $(F(\mathrm{I}, 42)<\mathrm{I})$. Thus, familiarization times were comparable across conditions at each age.

\section{Test phase}

Mean orientation times to the passages containing the familiarized words and to the passages containing the control bisyllabic words were calculated for each infant (see Figure I, and also summary of all experiments, Table I). A 3-way ANOVA with the between-subject factors of age $(0 ; 8,1 ; 0$, and I ;4) and condition (familiarization with béret-surprise versus devis-guitare) and the within-subject factor of familiarity (familiar versus control) was conducted. The effect of age was significant $(F(2,42)=5.65, p=\cdot 007$, $\eta_{p}^{2}=\cdot 2 \mathrm{I} 2$ (small size)), due to longer orientation times at $0 ; 8(M=8 \cdot 43 \mathrm{~s}$, $S D=2 \cdot 08)$ compared to $\mathrm{I} ; \circ(M=6 \cdot 70 \mathrm{~s}, S D=2 \cdot 42)$ and I $44(M=6 \cdot$ I० s, $S D=2 \cdot 18)$.

The effect of familiarity was also significant $(F(\mathrm{I}, 42)=8 \cdot 43, p=\cdot 006$, $\eta_{p}^{2}=\cdot_{\mathrm{I}} 67$ (small size)), indicating that the infants had longer orientation times to the passages with the familiarized words $(M=7 \cdot 48 \mathrm{~s}, S D=2 \cdot 47)$ than to those with the control words $(M=6.68 \mathrm{~s}, S D=2 \cdot 34)$. However, there was a significant familiarity $\times$ age interaction $(F(2,42)=3 \cdot 79, p=\cdot 03 \mathrm{I}$, 


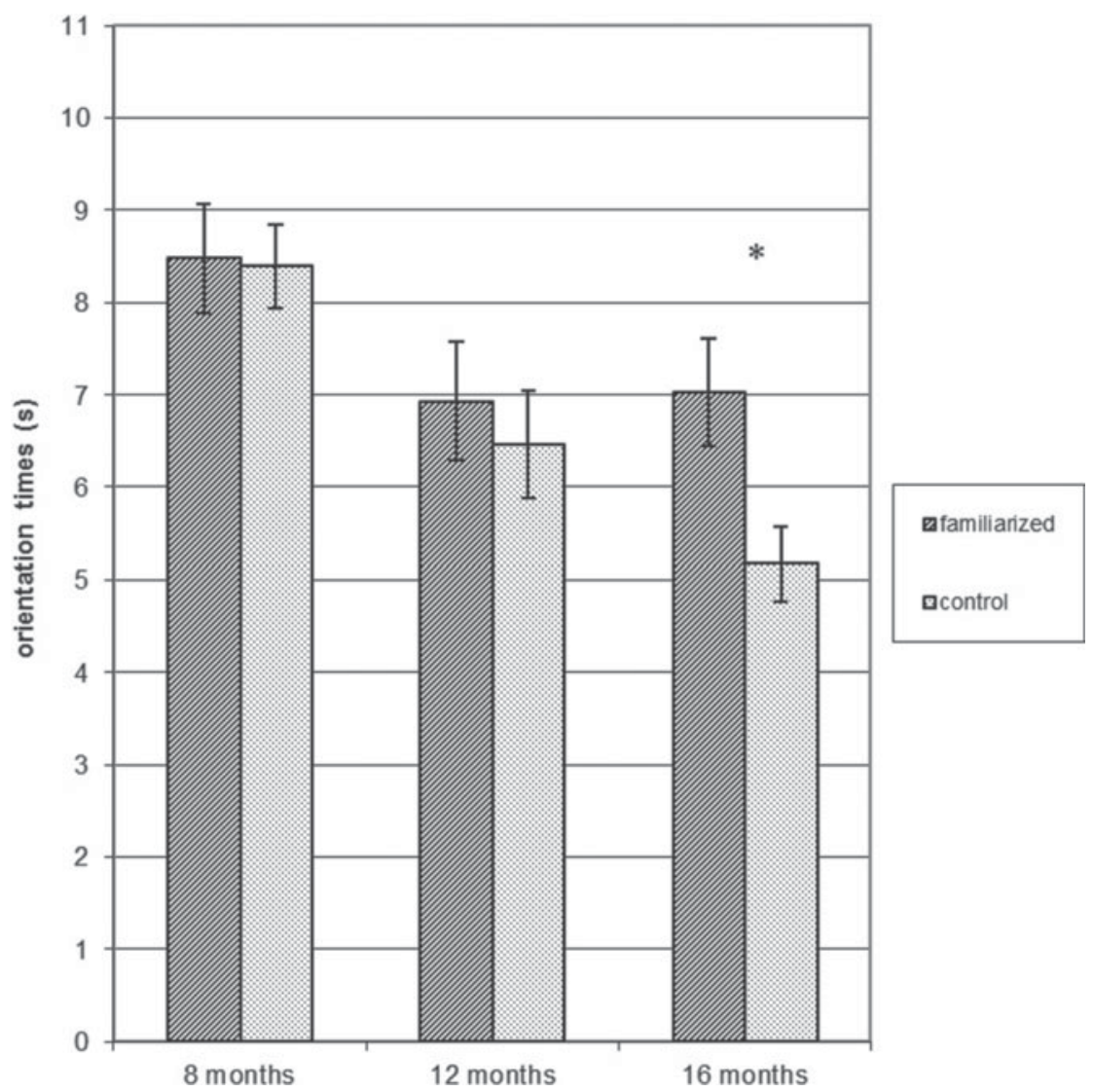

Fig. I. Mean orientation times (s) to the test passages containing the familiarized bisyllabic words or the control words (Experiment I, word-passage order, standard European French stimuli, $30 \mathrm{~s}$ familiarization). The error bars indicate the standard error of the mean. Left panel : 8-month-old infants; central panel: I 2-month-old infants; right panel: I6-month-old infants.

$\eta_{p}^{2}=\cdot{ }_{53}$ (small size)), indicating that the effect of familiarity changed with age.

No other effect or interaction reached significance (all $F_{\mathrm{s}}<\mathrm{I}$ ).

In order to specify the familiarity $\times$ age interaction, planned comparisons were conducted. The effect of familiarity failed to reach significance at $0 ; 8$ $\left(F(\mathrm{I}, 42)=0.02, p=.89, \eta_{p}^{2}=.00 \mathrm{I}\right)$, indicating that these infants had similar orientation times to the passages with the familiarized $(M=8 \cdot 48 \mathrm{~s}, S D=2 \cdot 36)$ and control $(M=8 \cdot 39 \mathrm{~s}, S D=\mathrm{r} \cdot 84)$ words. Only nine of the sixteen infants oriented longer to the passages with the familiarized words. The effect of familiarity also failed to reach significance at $\mathrm{I} ; \mathrm{O}(F(\mathrm{I}, 42)=\mathrm{I} \cdot 45, p=\cdot 25$, 
$\eta_{p}^{2}=$.094), indicating that these infants had similar orientation times to the passages with the familiarized $(M=6.93 \mathrm{~s}, S D=2.55)$ and control $(M=6 \cdot 46 \mathrm{~s}, S D=2 \cdot 34)$ words. Again, only nine of the sixteen infants oriented longer to the passages with the familiarized words. However, the effect of familiarity was significant at $\mathrm{I} ; 4(F(\mathrm{I}, 42)=\mathrm{I} 5.02, p<\cdot 00 \mathrm{I}$, $\eta_{p}^{2}=\cdot 549$ (large size)), indicating that these infants had longer orientation times to the passages with the familiarized $(M=7.02 \mathrm{~s}, S D=2.33)$ than control $(M=5 \cdot \mathrm{I} 7 \mathrm{~s}, S D=\mathrm{I} \cdot 6 \mathrm{I})$ words. This pattern of preference was found for thirteen of the sixteen infants.

In the present experiment, Parisian French-learning infants were familiarized with two bisyllabic words and then tested with passages either containing these words or containing control bisyllabic words. No evidence for segmentation was found at either $0 ; 8$ or $\mathrm{I} ; 0$, although evidence for word segmentation was found at i;4 (large size effect). These results replicate Nazzi et al.'s (2006) earlier findings with Parisian infants and diverge from Polka and Sundara's (2012) results with Canadian French-learners, who successfully segmented the same stimuli when tested using the same procedure at $\circ ; 8$. These results show that differences in test procedure (i.e., familiarization duration) or degree of infant-directed speech alone cannot fully account for the lack of segmentation effect in Parisian French infants at $0 ; 8$ and I; 0 found by Nazzi et al. (2006). This is consistent with the alternative view, proposed earlier, that Parisian French-learning infants are at a disadvantage in terms of segmentation abilities compared to Canadian French infants.

\section{EXPERIMENT 2}

Although Experiment I clearly establishes dialect differences in French word segmentation, there are questions remaining as to the extent of these differences and in particular whether Parisian infants might be able to segment bisyllabic words in natural speech under certain conditions at o; 8 . As mentioned earlier, the results of Mersad and Nazzi (2012) suggest this possibility. In their Experiment I, Parisian infants aged $\circ ; 8$ were presented with a continuous string of four trisyllabic words repeated in pseudorandom order. After 3 minutes of familiarization, infants were able to distinguish the target trisyllabic words from trisyllabic part-words, thus establishing that they could segment the signal into multisyllabic words using transitional probabilities. However, infants failed to segment when the words of the language did not have the same number of syllables, unless the language contained the known word maman (mommy, in French).

How do these results bear on the present study? Two major differences might explain the different outcomes for the two studies. First, in the artificial language study there were only four (unknown) words, while in the 
present study, the passages were made up of dozens of different words. Hence Parisian infants might segment bi/multisyllabic words only in very constrained situations. Another important difference is that in Mersad and Nazzi (2012), infants were familiarized with continuous speech and then tested on isolated word forms, while infants in Experiment I were familiarized with isolated words and then tested on passages. Exposure to the passages first might allow infants to compute some distributional analyses of the input, and notice that some syllables often occur together (have high transitional probabilities).

Accordingly, we hypothesized that better segmentation results might be obtained with Parisian infants if we replicated Experiment I using a passage-word rather than a word-passage order. Infants may perform better because the passages used in the present study each contain a given target word that is repeated six times, so that the two syllables of the target bisyllabic words are those that occur together in the passages most frequently. If hearing the passages in the familiarization phase allows infants to pick up on this regularity, then they might be able to segment them and subsequently recognize the target bisyllabic words presented in isolation. Therefore, in Experiment 2, Parisian infants aged $0 ; 8$ were presented with the Polka and Sundara (2012) standard European French stimuli used in Experiment I, with the crucial methodological difference that they were familiarized with passages and then tested with the isolated words, rather than the other way round.

\section{METHOD}

\section{Participants}

Twenty-four infants from French-speaking families living in the Paris area were tested at age $0 ; 8(M=0 ; 8 \cdot 08$; range: $0 ; 8 \cdot 00-0 ; 8 \cdot 26$; I 3 girls, I I boys). The data of six additional infants were excluded (fussiness/crying: 4; experimental error: 2).

\section{Stimuli}

The stimuli were the standard European French stimuli from Experiment I.

\section{Procedure, apparatus, and design}

The procedure was similar to that of Experiment I, with the crucial difference that the order of word lists and passages was reversed: the passages were presented in the familiarization phase and the word lists in the test phase. Familiarization lasted until infants had accumulated at least $30 \mathrm{~s}$ to each passage, and the test phase consisted of twelve trials (3 blocks each 
presenting the 4 word lists). While Jusczyk et al. (I999b) used different durations of familiarization in the word-passage (30 s) and passage-word $(45 \mathrm{~s})$ order, we used the same duration in both Experiments $\mathrm{I}$ and 2 so that a change in performance between the two experiments could not simply be due to a difference in duration of familiarization. The apparatus was identical to that of Experiment I. Half of the infants were familiarized with the passages béret and surprise, and the other half with the passages devis and guitare.

\section{RESULTS AND DISCUSSION}

\section{Familiarization phase}

Mean orientation time during familiarization was $40.8 \mathrm{~s}$, and there was no difference between the two familiarization conditions $\left(t(22)=I_{1} I_{5}, p=\cdot 26\right)$.

\section{Test phase}

Mean orientation times to the bisyllabic words corresponding to the familiarized passages and to the control words were calculated for each infant (see Figure 2, left panel). A 2-way ANOVA with the between-subject factor of condition and the within-subject factor of familiarity was conducted. There was a significant effect of familiarity $(F(\mathrm{I}, 22)=5 \cdot 82, p=\cdot 025$, $\eta_{p}^{2}=\cdot 209$ (small effect)), infants having longer orientation times to the familiarized $(M=9.33 \mathrm{~s}, S D=3.06)$ than control $(M=8 \cdot \mathrm{s} \circ \mathrm{s}, S D=2 \cdot 65)$ words. Sixteen out of twenty-four infants showed longer orientation times to the familiarized words. There was no effect of condition $(F(\mathrm{I}, 22)=2 \cdot 73$, $p=\cdot \mathrm{I} I)$, and no familiarity $\times$ condition interaction $(F(\mathrm{I}, 22)<\mathrm{I})$. Note that a similar pattern of results was found when analyzing the results of the first sixteen infants, although the familiarity effect failed to reach significance (familiar: $M=9.73 \mathrm{~s}$; control: $M=8.72 \mathrm{~s} ; F(\mathrm{I}, \mathrm{I} 4)=3.2 \mathrm{I}, p=\cdot 09$ ).

The present results establish that segmentation effects using bisyllabic words embedded in complex natural sentences can be found at age $0 ; 8$ in Parisian French-learning infants under some circumstances, specifically when infants are familiarized with passages containing target words, and then tested on repetitions of isolated words. This result $\left(\eta_{p}^{2}=\cdot 209\right)$ clearly differs from the evidence obtained by Nazzi et al. (2006) and in the present Experiment I $\left(\eta_{p}^{2}=\cdot \circ \mathrm{I}\right.$ at $\left.\circ ; 8\right)$, establishing that Parisian French infants aged $0 ; 8$ show segmentation effects with bisyllabic words in the passageword order, but not the word-passage order. This effect is compatible with the possibility that infants in Experiment 2 segmented the bisyllabic words. However, before reaching such a conclusion, Experiment 3 explored the possibility that they might have segmented or recognized only part of the target bisyllabic words. 


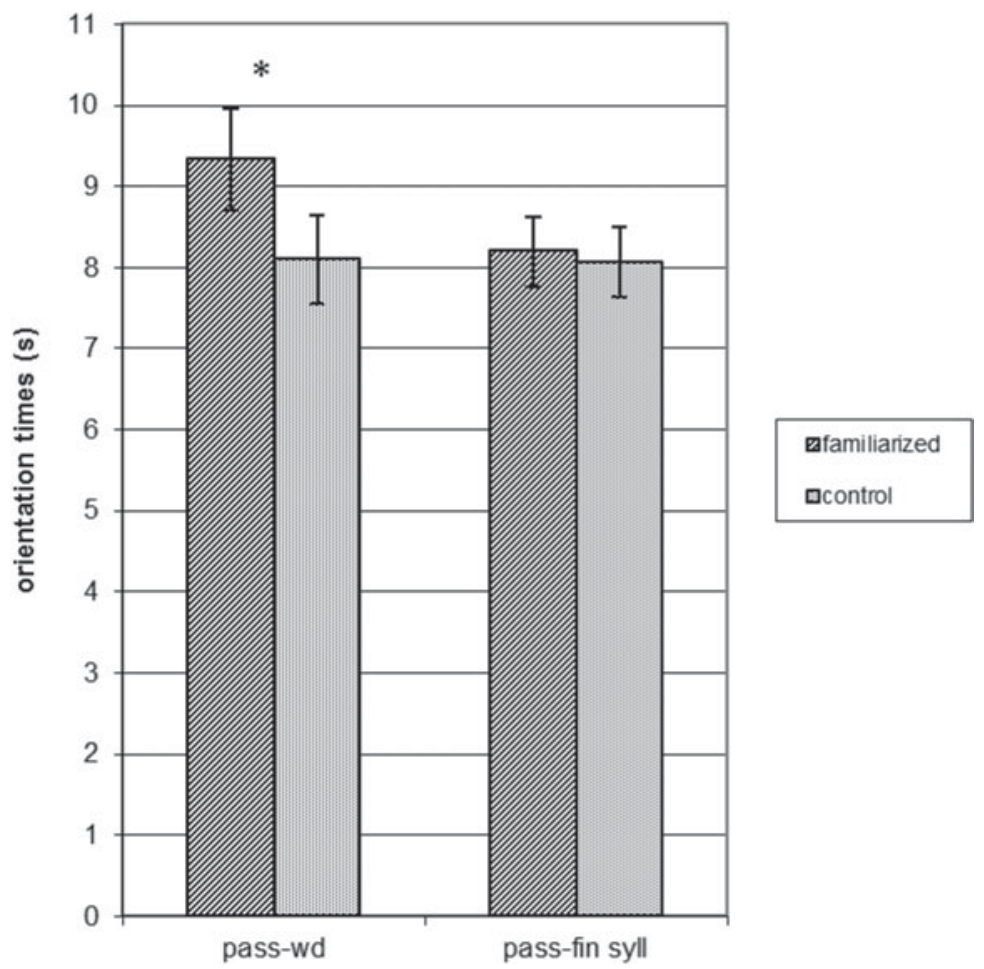

Fig. 2. Mean orientation times (s) to the test items corresponding to the familiarized bisyllabic words or the control words (Experiments 2-3, standard European French stimuli, $30 \mathrm{~s}$ familiarization, 8-month-old infants). The error bars indicate the standard error of the mean. Left panel: passage-word order; right panel: passage-final syllable order.

\section{EXPERIMENT 3}

Recall that French has phrase-final lengthening resulting in longer final syllables, as was the case for the bisyllabic words used in Experiments I and 2, and that Nazzi et al. (2006) found that final syllables are easier to segment or recognize by Parisian French-learners at $\mathrm{I} ; 0$ (in the word-passage order). Given these facts, one might conjecture that infants in Experiment 2 did not recognize the bisyllabic words themselves, but only a portion of these words, in particular the final, more salient syllables. Experiment 3 tested this possibility. Accordingly, infants were familiarized with the same passages as infants in Experiment 2, but presented at test with isolated final syllables that corresponded either to the familiarized words or to the control words. As done in Experiment 4 of Nazzi et al. (2006) and in Experiment 2 of Polka and Sundara (2012), these isolated final syllables were spliced from the target words produced in isolation for Experiments I and 2. If infants in 
Experiment 2 have segmented the bisyllabic words as such, they should not show segmentation of the isolated final syllables, i.e., they should listen equally to familiar and novel syllables in the test phase (following previous findings by Jusczyk et al., ı 999b; Nazzi et al., 2006; Polka \& Sundara, 2012).

METHOD

\section{Participants}

Twenty-four infants from French-speaking families living in the Paris area were tested at age $0 ; 8(M=0 ; 8 \cdot$ I 8 ; range: $0 ; 8 \cdot 03-0 ; 8 \cdot 30$; I I girls, I 3 boys $)$. The data of three additional infants were excluded for fussiness/crying.

\section{Stimuli}

The passages were the standard European French stimuli from Experiments I and 2. The syllables presented at test were the spliced final syllables from the four target words used in Experiments I and 2: ret, prise, vis, and tare. The average duration of the lists was $20.6 \mathrm{~s}(S D=0 \cdot 6)$. The target final syllables spoken in isolation had an average duration of $387 \mathrm{~ms}$ (béret: $280 \mathrm{~ms}$; surprise: $547 \mathrm{~ms}$; guitare: $496 \mathrm{~ms}$; devis : $274 \mathrm{~ms}$; average pause duration $843 \mathrm{~ms}$ ).

\section{Procedure, apparatus, and design}

The procedure was similar to that of Experiment 2, with one crucial difference: after familiarizing infants with the passages, as done in Experiment 2, infants were presented at test with either the final syllables of the familiarized words, or the final syllables of the control words (ret and prise versus vis and tare, depending on the familiarization condition). The test phase consisted of twelve trials ( 3 blocks each presenting the 4 final syllable lists). The apparatus was identical to that of Experiments I and 2. Half of the infants were familiarized with the passages beret and surprise, and the other half with the passages devis and guitare.

\section{RESULTS AND DISCUSSION}

\section{Familiarization phase}

Mean orientation time during familiarization was $38.7 \mathrm{~s}$, and there was no difference between the two familiarization conditions $(t(22)=\mathrm{I} \cdot 33, p=\cdot 20)$.

\section{Test phase}

Mean orientation times to the final syllables of the bisyllabic words corresponding to the familiarized passages and to the final syllables of the 
control words were calculated for each infant (see Figure 2, right panel). A 2-way ANOVA with the between-subject factor of condition and the within-subject factor of familiarity was conducted. There was no effect of familiarity $\left(F(\mathrm{I}, 22)=0 \cdot 10, p=\cdot 75, \eta_{p}^{2}=\cdot 005\right)$, indicating that the infants had similar orientation times to the final syllables of the familiarized $(M=8 \cdot 20 \mathrm{~s}, S D=2 \cdot \mathrm{I} 2)$ and control $(M=8.06 \mathrm{~s}, S D=2 \cdot \mathrm{I} 2)$ words. Eleven out of twenty-four infants showed longer orientation times to the final syllables of the familiarized words. There was no effect of condition $(F(\mathrm{I}, 22)=3 \cdot 59, p=\cdot 07)$, and no familiarity $\times$ condition interaction $(F(\mathrm{I}, 22)=$ $\left.2 \cdot 46, p=\cdot \mathrm{I}_{3}\right)$.

The present results do not provide any evidence that at age $0 ; 8$ Parisian French-learners recognized the final syllables of the target bisyllabic words that were presented to them in passages during familiarization $\left(\eta_{p}^{2}=\cdot 0_{0}\right)$, while such infants recognized these target bisyllablic words in Experiment 2 $\left(\eta_{p}^{2}=\cdot 209\right.$, small effect). Taken together, and in light of previous results (Jusczyk et al., I999b; Nazzi et al., 2006; Polka \& Sundara, 2012), this establishes that infants in Experiment 2 were recognizing the target words as whole bisyllabic units, rather than recognizing their individual syllables (we only tested the most salient final syllables, but predict similar results for the less salient initial syllables).

This pattern of results thus establishes that Parisian French-learning infants are segmenting bisyllabic words at basically the same age at which this ability has been reported for Canadian French, and for other languages such as English and Dutch, at least when presented with the passage-word order (while this ability was found at a later age for Parisian infants tested in the word-passage order). Our results also extend the findings reported by Mersad and Nazzi (2012) using a simple four-word artificial language. Therefore, the ability to segment bisyllabic words does not emerge later in infants acquiring European French but, in fact, is evident when these infants are tested under conditions that are closer to what is required of them in everyday speech processing. Hence, Experiments $\mathrm{I}-3$ allow us to better understand the differences in results found by Nazzi et al. (2006) and Polka and Sundara (2012). Experiment I established that these differences were not due to methodological differences between the two studies (use of different stimuli, or different familiarization times). Moreover, Experiments 2 and 3 showed that the difference in the original results was not due to Parisian infants' complete inability to segment bisyllabic words, by establishing, for the first time, such an ability in Parisian Frenchlearners at $0 ; 8$.

What our findings show is that Parisian and Canadian infants in fact partly differ in their segmentation abilities, in the sense that Canadian infants succeed at segmenting bisyllabic words in some conditions under which Parisian infants fail, suggesting that segmentation is not achieved 
in exactly the same way in Parisian and Canadian French infants. In the following three experiments, we will explore how dialect differences affect segmentation, by exploring how Parisian infants segment Canadian French stimuli.

\section{EXPERIMENT 4}

Why do Canadian French-learning infants have an advantage in word segmentation? One logical possibility is that the advantage is due to dialectal differences, such that hearing Canadian French confers a segmentation advantage. This advantage might arise from months $(8$ months at most) of experience with Canadian French input. Alternatively, there may be an immediate advantage, i.e., word boundaries might be marked more clearly in Canadian French than in standard European French stimuli, which may facilitate segmentation even without prior exposure to the dialect. In Experiment 4, we explore this latter hypothesis by testing Parisian French-learners at $\circ ; 8$ on the Canadian French stimuli used by Polka and Sundara (2012).

Analyses conducted by Polka and Sundara (2012) reveal some acoustic differences between their standard European French and Canadian French stimuli. For each set of French stimuli, they measured the acoustic correlates of stress (duration, amplitude, and pitch) of each syllable of the target bisyllabic words, both for the list words and for the words within the passages. Values for the Canadian French stimuli are reported in Table 2 (right columns). For passages, the second syllable of these bisyllabic words was significantly longer $(t(23)=5 \cdot 6 \mathrm{I}, p<\cdot 000 \mathrm{I}, d=\mathrm{I} \cdot 57)$, but there were no significant differences in the intensity $(t(23)=-\mathbf{I} \cdot 7, p=\cdot 09)$ or mean Fo of the two syllables $(t(23)<\mathrm{I})$. For list words, the second syllable of these bisyllabic words was significantly longer $\left(t(55)=I_{5} \cdot 8\right.$, $p<\cdot 00 \mathrm{I}, d=\mathrm{I} 8 \cdot 6)$, had a greater intensity $(t(55)=2 \cdot \mathrm{I} 3, p=\cdot 038, d=0.4 \mathrm{I})$, and a higher mean Fo $(t(55)=-2 \cdot 04, p=\cdot 046, d=-0 \cdot 35)$, compared to the first syllables.

Comparing the acoustic characteristics of the stimuli across the two dialects, we see that, overall, the standard European French words were consistently shorter than the Canadian French words, reflecting a faster speech rate in standard European French. In both dialects, clear differences were observed (final syllables longer than initial syllables) for the list words and for the words within the passages. There were no reliable differences in the size of this duration difference across the two dialects, but standard European French words were less variable in duration compared to Canadian French words. For the Canadian French words, pitch and amplitude differences (both higher on final syllables) were also evident in the list words but not for the passage words. In contrast, for the standard 
European French words, the syllables differed in amplitude, but not in pitch, for both list words and passage words.

These analyses indicate that there was clearer prosodic marking in the Canadian French words than in the standard European French words, with more acoustic cues supporting an iambic stress pattern for the Canadian French words than the standard European French words, at least with respect to the list words. This property of Canadian French stimuli may make segmentation easier for Parisian French infants, assuming that they benefit from hearing a more coherent prosodic word form during familiarization. Therefore, we tested Parisian French infants aged $0 ; 8$ on the Canadian French stimuli. We first used the word-passage order, implementing the same procedure as Experiment I, in which they failed to show evidence of segmentation with European French stimuli.

\section{METHOD}

\section{Participants}

Sixteen infants from French-speaking families living in the Paris area were tested at o; 8 ( $M=0 ; 8 \cdot 23$; range: o;8.08-0;8.3 I; I I girls, 5 boys). The data of three additional infants were excluded for fussiness/crying.

\section{Stimuli}

The Canadian French stimuli and recordings were those used in Experiment I of Polka and Sundara (2012). All recordings were made in a sound-attenuated booth by a female talker who was a native speaker of Canadian French. The four target bisyllabic words and associated passages were the same as those recorded by the standard European French speaker. The passages were on average $2 \mathrm{I} \cdot 3 \mathrm{~s}$ long. The target bisyllabic words in the sentences had an average duration of $578 \mathrm{~ms}$ (béret: $5 \mathrm{I} 8 \mathrm{~ms}$; surprise: $743 \mathrm{~ms}$; guitare: $539 \mathrm{~ms}$; devis: 5 I $4 \mathrm{~ms}$ ).

The four associated lists were on average $2 \mathrm{I} \cdot 7 \mathrm{~s}$ long, and each contained thirteen to sixteen isolated occurrences of a target word produced with some variation. The target bisyllabic words spoken in isolation had an average duration of 742 (béret: $546 \mathrm{~ms}$; surprise: $989 \mathrm{~ms}$; guitare: $687 \mathrm{~ms}$; devis: $733 \mathrm{~ms}$; average pause duration $=700 \mathrm{~ms}$ ).

\section{Procedure, apparatus, and design}

The procedure and apparatus were identical to those of Experiment I. Infants received twelve test passages (3 blocks with 4 passages in each block). Half of the infants were familiarized with the nouns béret and surprise, and the other half with the nouns devis and guitare. 


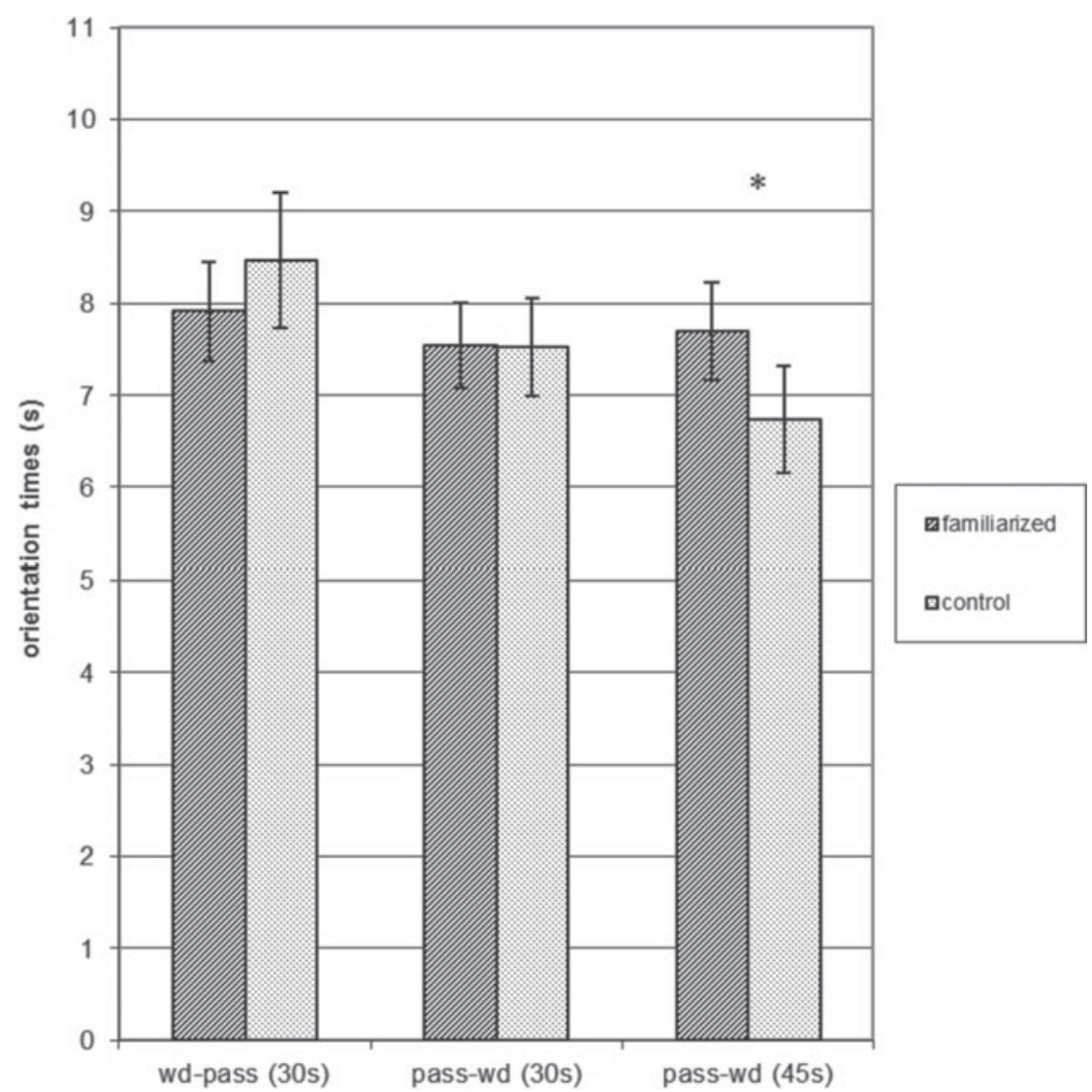

Fig. 3. Mean orientation times (s) to the test items corresponding to the familiarized bisyllabic words or the control words (Experiments 4-6, Canadian French stimuli, 8-monthold infants). The error bars indicate the standard error of the mean. Left panel: word-passage order (30 s familiarization); central panel: passage-word order (30 s familiarization); right panel: passage-word order (45 $\mathrm{s}$ familiarization).

\section{RESULTS AND DISCUSSION}

\section{Familiarization phase}

Mean orientation time during familiarization was $38.6 \mathrm{~s}$, and there was no difference between the two familiarization conditions $\left(t\left(\mathrm{I}_{4}\right)<\mathrm{I}\right)$.

\section{Test phase}

Mean orientation times to the passages containing the familiarized bisyllabic words and to the passages containing the control bisyllabic words were calculated for each infant (see Figure 3, left panel). A 2-way ANOVA 
with the between-subject factor of condition and the within-subject factor of familiarity was conducted. There was no effect of familiarity $\left(F(\mathrm{I}, \mathrm{I} 4)=0.97, p=\cdot 34, \eta_{p}^{2}=.065\right)$, indicating that the infants had similar orientation times to the passages containing the familiarized $(M=7 \cdot 9 \mathrm{I}$ s, $S D=2 \cdot 7 \mathrm{I})$ and control $(M=8.47 \mathrm{~s}, S D=2 \cdot 94)$ words. Only six infants out of sixteen showed longer orientation times to the passages with the familiarized words. There was no effect of condition $(F(\mathrm{I}, \mathrm{I} 4)<\mathrm{I})$, and no familiarity $\times$ condition interaction $\left(F(\mathrm{I}, \mathrm{I} 4)=4 \cdot 27, p=\cdot 06, \eta_{p}^{2}=\cdot 234\right)$.

The present results again fail to provide evidence that Parisian French-learning infants are able to segment bisyllabic words from fluent speech in the word-passage order $\left(\eta_{p}^{2}=\cdot 06_{5}\right)$. These results are in line with those of Nazzi et al. (2006) and those of the present Experiment I. They again contrast with the results found for Canadian French infants, who could segment at age $0 ; 8$ in the word-passage order, both the standard European French and the Canadian French stimuli used in Experiment I and 2 respectively (Polka \& Sundara, 2012, with large effect sizes), confirming our interpretation of previous findings in terms of dialectal differences in word segmentation abilities.

The present results also help to discard some possibilities explaining the segmentation advantage of the Canadian over the Parisian infants. As discussed earlier, while the results from Experiment I suggested that hearing Canadian French confers a segmentation advantage, it was unclear whether such advantage was due to months of experience with Canadian French input, or whether Canadian French provides a cue to segmentation that could be grasped right away when hearing Canadian French stimuli. This latter hypothesis is clearly not supported by the present experiment. Therefore, it appears that word segmentation abilities differ not only crosslinguistically, but also across dialects, and that in both cases the differences observed around $0 ; 8$ are not due to procedural differences or indexical properties of the stimuli presented, but are due to infants using at least partly different segmentation processes across languages and across dialects. Hence it appears that by $\circ ; 8$, differences in the properties of the native languages/dialects underlie differences in the way (French-learning) infants segment fluent speech.

\section{EXPERIMENT 5}

Experiment 4 failed to find evidence of cross-dialect segmentation by Parisian infants in the word-passage order. Experiments 5 and 6 explored whether Parisian infants are able to segment Canadian French stimuli in the passage-word order, a protocol that appeared easier to them when processing Parisian French (Experiment I versus 2). Accordingly, in Experiment 5, Parisian French infants were tested on Canadian French 
materials using the same procedure as in Experiment 2, where infants were first familiarized for $30 \mathrm{~s}$ with the target words in passages and then presented with isolated words during the test phase. Experiment 6 will extend Experiment 5 by increasing duration of familiarization to $45 \mathrm{~s}$, the value used in Jusczyk et al. (r $999 \mathrm{~b})$.

\section{METHOD}

\section{Participants}

Twenty-four infants from French-speaking families living in the Paris area were tested at age $0 ; 8(M=0 ; 8 \cdot 17$; range: $0 ; 7 \cdot 24-0 ; 9 \cdot 03$; I I girls, I 3 boys $)$. The data of three additional infants were excluded for fussiness/crying.

\section{Stimuli}

The stimuli were the Canadian French stimuli from Experiment 4.

\section{Procedure, apparatus, and design}

The procedure, apparatus and design were identical to that of Experiment 2.

\section{RESULTS AND DISCUSSION}

\section{Familiarization phase}

Mean orientation time during familiarization was $38.6 \mathrm{~s}$, and there was no difference between the two familiarization conditions $(t(22)<\mathrm{I})$.

\section{Test phase}

Mean orientation times to the bisyllabic words corresponding to the familiarized passages and to the control words were calculated for each infant (see Figure 3, middle panel). A 2-way ANOVA with the betweensubject factor of condition and the within-subject factor of familiarity was conducted. There was no effect of familiarity $(F(\mathrm{I}, 22)=0.00 \mathrm{I}, p=.97$, $\left.\eta_{p}^{2}=\cdot 000\right)$, indicating that the infants had similar orientation times to the familiarized $(M=7 \cdot 54 \mathrm{~s}, S D=2 \cdot 23)$ and control $(M=7 \cdot 53 \mathrm{~s}, S D=2 \cdot 93)$ words. Ten out of twenty-four infants showed longer orientation times to the familiarized words. There was no effect of condition and no familiarity $x$ condition interaction (both $F(\mathrm{I}, 22)<\mathrm{I}$ ).

The present results fail to provide evidence that Parisian French infants aged $0 ; 8$ can segment bisyllabic words when the stimuli presented are in Canadian French $\left(\eta_{p}^{2}=\cdot 0 \circ\right)$. Given that they were successful under exactly the same experimental conditions when presented with stimuli in standard 
European French $\left(\eta_{p}^{2}=\cdot 209\right.$, small effect), these results establish that Parisian French infants do not process both types of stimuli with equal ease. These results again show differences between Parisian and Canadian infants at $\circ ; 8$, since the latter could segment both types of stimuli under the same experimental conditions (the word-passage order that Parisian infants failed in Experiments I and 4).

\section{EXPERIMENT 6}

In Experiment 6, we explored whether Parisian French infants might succeed at segmenting Canadian French stimuli when they are given a little more time to process the stimuli. This step was motivated by the fact that a longer familiarization time $(45 \mathrm{~s})$ was used for the passage-word order in Jusczyk et al. (1999b). Thus, Experiment 6 is a replication of Experiment 5, the only difference being that the criterion for familiarization to each passage was increased from $30 \mathrm{~s}$ to $45 \mathrm{~s}$.

\section{METHOD}

\section{Participants}

Sixteen infants from French-speaking families living in the Paris area were tested at age $\circ ; 8(M=0 ; 8 \cdot 26$; range: $0 ; 8 \cdot 22-0 ; 8 \cdot 30$; Io girls, 6 boys $)$. The data of three additional infants were excluded for fussiness/crying.

\section{Stimuli}

The stimuli were the Canadian French stimuli used in Experiments 4-5.

\section{Procedure, apparatus, and design}

The procedure, apparatus, and design were identical to that of Experiment 5, with the only crucial difference that the criterion of familiarization with the passages was increased from $30 \mathrm{~s}$ to at least $45 \mathrm{~s}$ for each passage.

\section{RESULTS AND DISCUSSION}

\section{Familiarization phase}

Mean orientation time during familiarization was $49.6 \mathrm{~s}$, and there was no difference between the two familiarization conditions $\left(t\left(\mathrm{I}_{4}\right)<\mathrm{I}\right)$.

\section{Test phase}

Mean orientation times to the bisyllabic words corresponding to the familiarized passages and to the control bisyllabic words were calculated for each

$$
624
$$


infant (see Figure 3, right panel). A 2-way ANOVA with the betweensubject factor of condition and the within-subject factor of familiarity was conducted. There was a significant effect of familiarity $(F($ I, I 4$)=5 \cdot 44$, $p=\cdot{ }^{\circ} 3, \eta_{p}^{2}=\cdot 280$ ), indicating that the infants had longer orientation times to the familiarized words $(M=7 \cdot 70 \mathrm{~s}, S D=2 \cdot \mathrm{II})$ than to the control words $(M=6 \cdot 73 \mathrm{~s}, S D=2 \cdot 32)$. Fourteen out of sixteen infants showed longer orientation times to the familiarized words. There was no effect of condition and no familiarity $\times$ condition interaction (both $\left.F\left(\mathrm{I}, \mathrm{I}_{4}\right)<\mathrm{I}\right)$.

The present results establish that Parisian infants are able to segment bisyllabic words from fluent speech when presented with stimuli in a non-native (Canadian) dialect. This finding is congruent with the finding by Polka and Sundara (2012) of cross-dialect segmentation by Canadian French infants. However, contrary to the results with Canadian French infants, our results suggest that there is a cost in segmenting the non-native dialect, since successful segmentation required a longer familiarization with the passages (significant effect with $45 \mathrm{~s}$ in Experiment $6, \eta_{p}^{2}=\cdot 280$, medium effect, but non-significant effect with $30 \mathrm{~s}$ in Experiment $5, \eta_{p}^{2}=\cdot 000$ ). This difference in cost associated with non-native dialect segmentation is another sign that Parisian and Canadian infants have partly different segmentation skills.

\section{GENERAL DISCUSSION}

The goal of the present study was to reassess Parisian French-learning infants' ability to segment bisyllabic words from fluent speech at o; 8 . This reassessment was motivated by two recent lines of research showing very different results with respect to the emergence of bisyllabic word segmentation in Parisian infants (between I; 0 and I; 4 for Nazzi et al., 2006, HPP study; by I; o for Goyet et al., 2010, ERP study) and Canadian French infants (by o;8 for Polka \& Sundara, 2012), along with differences in performance between Parisian infants when tested in an artificial language paradigm (Mersad \& Nazzi, 2012) and a natural language paradigm (Nazzi et al., 2006). This earlier work in our labs suggested that word segmentation skills emerge later in development for infants acquiring European French, particularly in tasks that involve processing natural speech. Given the implications that such language-specific differences would have for understanding the mechanisms underlying early speech segmentation, we explored several possibilities for the differences found between the Nazzi et al. (2006) and Polka and Sundara (2012) findings.

\section{Bisyllabic word segmentation revisited}

One potential explanation for the differences found between these studies was the different stimuli and slightly different testing methods used in each 
lab. Crucially, these differences could have favored infants tested by Polka and Sundara (2012). The results of Experiment I, in which Parisian infants were tested using the exact stimuli and procedures (in the word-passage order) as Polka and Sundara (2012) showed bisyllabic word segmentation at I; 4 but not $0 ; 8$ or $\mathbf{I} ; 0$. These findings confirm that previously reported differences in performance between Parisian and Canadian French infants cannot be fully explained by stimuli/procedure differences alone. This outcome shows that, at least in some test conditions, Parisian infants have more difficulty segmenting bisyllabic words compared to their Canadian French peers.

However, the results of Experiments 2 and 3 (and then Experiment 6 for data with Canadian French stimuli) establish for the first time that, when task demands are altered, Parisian French-learning infants can segment bisyllabic words from fluent speech when presented with complex natural language stimuli by $0 ; 8$. While the results of Experiment 2 show recognition of bisyllabic words previously presented in passages, the results from Experiment 3 suggest that infants were not simply recognizing the more salient, final syllables of these words. These results thus extend the recent finding of trisyllabic word segmentation in the same population when infants are tested with simple, controlled stimuli in an artificial language paradigm (Mersad \& Nazzi, 2012). Therefore, contrary to previous findings (Gout, 200I; Nazzi et al., 2006; present Experiment I), the ability to segment bisyllabic word forms does not emerge later when infants are acquiring European French. Interestingly, though, we found that the order in which the isolated words and the passages were presented had a crucial impact on segmentation performance of Parisian infants at $\circ ; 8$. They could segment bisyllabic words, but only if they were familiarized with the passages containing the bisyllabic words and then tested on the words in isolation, but not in the reverse order (words then passages), as attested by the comparison between Experiments $\mathrm{I}$ and 2 for standard European French stimuli (and Experiments 4 and 6 for Canadian French stimuli).

What could explain such a drastic change in infants' performance? On the surface it would seem that segmenting in the passage-word order would not be easier, given that infants in this condition are given the passages without any indication of what the target words are, while in the word-passage conditions, infants have heard the target words in isolation many times before they are presented with the passages to be segmented. However, the passage-word order might facilitate word segmentation for several reasons. First, this protocol is more akin to infants' situation outside the lab where they typically hear fluent speech that contains words to be segmented. Second, in the word-passage order, infants are processing passages during the test phase, and to succeed they must both segment the sentences and compare the outcome of their segmentation to the bisyllabic words encoded 
during the prior familiarization. Therefore, they are performing two processes (segmenting and comparing) at the same time. In contrast, when infants are processing word lists in the test phase of the task (as in the passage-word order), they need only match these word forms with the targets that have been previously segmented and memorized during familiarization. Therefore, processing demands during the test phase are likely to be lower in the passage-word order. A third factor that may contribute to order differences is that extracting the target words from the passages requires some minimal time listening to the passages. However, recall that in the word-passage condition there is only a minimal listening time of $3 \mathrm{~s}$ (about I sentence) to each passage in the test phase, since listening time is under the infant's control and tends to decrease across test trials. Thus, in the word-passage condition, infants typically do not listen to each passage as long as they do in the passage-word order, where every infant hears the passages for at least 30 (or 45) seconds before entering the test phase. In addition, in the passage-word order each infant is required to process only two passages, whereas in the word-passage condition each infant is required to process four passages ( 2 test and 2 control) presented in a semi-random order. Thus, in the word-passage order, the processing of the test passages is not only shorter but is interrupted by processing of the control passages.

Recall that no differences related to order (word-passage vs. passageword) have been reported in previous studies where both test orders have been implemented (although differences in effect sizes related to order were not analyzed statistically). This includes experiments in which Englishlearning infants aged o;8 were tested on monosyllabic (Jusczyk \& Aslin, I995) and trochaic bisyllabic words (Jusczyk et al., r 999b; but see van Heugten \& Johnson, 20I2). Why would this procedural difference affect segmentation performance for the Parisian French infants? One possibility, to be explored in future research, is that this order effect depends on the cues that infants are relying on. More specifically, as we have argued above, TP information might be easier to exploit in the passage-word order compared to the word-passage order. From this perspective, we predict no difference in performance between these test orders when infants are relying more on prosodic cues than TPs to segment bisyllabic words, whereas differences will emerge when infants are relying more on TPs than prosodic cues. The former case corresponds to the segmentation of trochaic words by English-learning infants, who rely more on prosodic cues between $0 ; 8$ and ०; I I (Johnson \& Jusczyk, 200I; Johnson \& Seidl, 2009). No order effects have been reported for these infants. The latter case might apply to segmentation by French-learning infants, who are most successful when they have TP information for syllabic units (e.g., Goyet et al., 2009 submitted; Nazzi et al., 2006). Accordingly, we predict a benefit to the 
passage-word order (over the word-passage order) for French-learning infants. This was found in the present study for Parisian French infants, and should be evaluated in the future for Canadian French infants who, while they succeeded in the word-passage order (Polka \& Sundara, 2012), might have even better performance in the passage-word order. Therefore, although the present study was not designed to specifically explore the cues infants rely on to segment bisyllabic words, our findings suggest that TP information may play an important role in the early acquisition of word segmentation skills in French-learning infants. By no means does this imply that prosody has no effect on segmentation in French, as discussed below.

\section{Cross-dialect segmentation differences}

While our results clarify the pattern of emergence of segmentation abilities in Parisian French-learning infants, they also reveal, along with the results of Polka and Sundara (2012), clear differences in performance between Parisian and Canadian French infants, supporting the hypothesis that infants acquiring these different dialects of French develop somewhat distinct segmentation skills. Indeed, in virtually identical testing situations, Parisian and Canadian French infants do not perform in the same way. On the one hand, Canadian infants could segment bisyllabic words in the word-passage order by $0 ; 8$ when presented with either Canadian and European French stimuli, with large size effects (Cohen $d$ s of 0.46 and 0.55 , respectively; Polka \& Sundara, 2012). On the other hand, Parisian infants failed to segment either one at the same age (Experiments I and $4 ; \eta_{p}^{2}$ of .०o I and $\cdot 0_{5}$, respectively). Therefore, Canadian infants appear to have more flexible segmentation abilities than their Parisian peers.

Moreover, the failure of Parisian infants at $0 ; 8$ to segment the Canadian French stimuli in the word-passage order establishes that Canadian French infants' success in Polka and Sundara (2012) is not simply due to indexical properties of the Canadian French stimuli that make word segmentation easier. Rather, it appears that each dialect group is processing the same stimuli in different ways; hence they must be relying on somewhat different cues or cue weightings to segment words as a result of regular exposure to their native dialect. Moreover, for Parisian infants, these biases do not shift after just a few minutes of exposure to Canadian French in the laboratory. Future research will have to identify these cross-dialect differences in cue weighting. Based on the findings that word-final accentuation is more salient for the Canadian French isolated words than the Parisian French isolated words (marked not only by longer duration, but also higher intensity and pitch), one possibility is that Canadian French infants rely more on the prosodic marking of word endings than Parisian infants. Since this increased marking of word endings was not found for the passages, this 
cross-dialect effect could result from the fact that the clearer marking of isolated words in their environment would have increased Canadian infants' attention to prosodic marking of word endings prior to being tested in the lab (together with the fact that such clearer prosodic marking in Canadian French might also be found in infant-directed sentences shorter than the ones used in the present study). It follows that they would have become more sensitive to such a cue in fluent speech, resulting in comparatively better performance compared to Parisian French infants when hearing the same stimuli, provided that these stimuli contain some prosodic marking of word endings (e.g., final syllable lengthening for our stimuli). This possibility will have to be directly tested in future research, together with the possibility that recording more speakers would reveal better marking of word endings in fluent Canadian than Parisian French.

In summary, combined with the results of Polka and Sundara (2012), the present results are the first to show differences in segmentation abilities across infants acquiring different dialects of the same language. It thus appears that segmentation abilities emerge and are shaped by input properties of the ambient language that may be shared across languages or dialects to varying degrees. Moreover, Canadian infants also appear to segment native and non-native French equally well (Polka \& Sundara, 20I2), while Parisian infants have more difficulties segmenting the stimuli in a non-native dialect (Experiments 2 and $5^{-6}$ ), an issue we turn to in the next section.

\section{Segmenting stimuli in native versus non-native dialects}

The present findings, together with prior work, show that infants as young as $0 ; 8$ can successfully segment word forms in an unfamiliar language (Houston, Jusczyk, Kuijpers, Coolen \& Cutler, 2000; Pelucchi, Hay \& Saffran, 2009) or dialect (Polka \& Sundara, 20I2), but this capacity is limited. Variation in the marking of word boundaries across languages/ dialects will induce differences in the weight given to these cues across languages/dialects, resulting in discrepancies in performance on the same material, as revealed in the present study and Polka and Sundara (2012).

Importantly though, the present findings also reveal that there can be a cost to segmenting in a foreign dialect (compared to the native one), as attested by the fact that at $0 ; 8$ the Parisian infants needed more familiarization with the passages containing the target bisyllabic words in order to segment and recognize them when presented with the non-native (Canadian) stimuli (Experiment $5: 30 \mathrm{~s}, p=\cdot 97, \eta_{p}^{2}=\cdot 000$; Experiment 6 : $45 \mathrm{~s}, \quad p=\cdot 035, \quad \eta_{p}^{2}=\cdot 280$ ) compared to the native (Parisian) stimuli (Experiment 2: $\left.30 \mathrm{~s}, p=\cdot 025, \eta_{p}^{2}=\cdot 209\right)$. This dialect effect contrasts with the findings by Polka and Sundara (2012) in which Canadian French infants 
could segment both Canadian and Parisian stimuli with the same amount of familiarization at $0 ; 8$.

There are several reasons (not mutually exclusive) why there might be a processing cost for speech produced in a non-native dialect. It is possible that the unfamiliarity of the speech stream (whether it originates from phonetic or prosodic mismatches between the two dialects) makes word segmentation harder. This is more likely to be the case early in development when infants have less expertise at word segmentation. Under this account, the cross-dialect segmentation advantage evident for Canadian French infants may have been due to differences in experience with the non-native dialect across the Canadian and Parisian infants tested in each study. Although possible, this is unlikely. French Canadian adults are probably more familiar with standard European French than French speakers of France are with Canadian French due to the wider influence of the standard European French media (especially TV and movies). However, Polka and Sundara (2012) excluded infants with regular exposure to English or to non-Canadian dialects of French from their study. Thus, any differences in cross-dialect exposure would be incidental and difficult to measure.

Another possible explanation lies in the existence of more variable intonation patterns at the sentence level in Canadian over European French (Menard et al., I 999). The pattern of results found comparing the present study with Polka and Sundara (2012) suggests that Parisian infants, learning the prosodically less variable dialect, incur a cost in segmenting the prosodically more variable dialect, while Canadian infants, learning the prosodically more variable dialect, can segment the prosodically less variable dialect without a cost. Therefore, one possible interpretation of the asymmetry in cross-dialect cost for Parisian and Canadian infants is that increased (sentence level) prosodic variability is having a negative impact on segmentation performance (possibly by distracting the infants). This adds to previous findings showing that word segmentation is very challenging for infants at o; 8 (see also Houston \& Jusczyk, 2000, 2003, for effects of gender differences, or Singh, Morgan \& White, 2004, and Thiessen et al., 2005, for effects of speech style).

Lastly, as discussed in the previous section, the fact that Canadian infants have more flexible segmentation abilities than Parisian infants at $0 ; 8$, as attested by their ability to segment in the word-passage order, might also have a positive impact on their ability to segment words in a non-native dialect.

To conclude, the present study reports three important findings. First, under certain conditions, i.e., with simple artificial languages (Mersad \& Nazzi, 20I2) and in the passage-word order with natural language stimuli (present study), Parisian infants are able to segment bi- and trisyllabic words from fluent speech at $0 ; 8$. Hence the ability to segment multisyllabic word forms does not emerge later in infants who are acquiring European 
French in comparison to infants acquiring other languages as previously suggested, given data from Nazzi et al. (2006). Second, for French-learning infants, dialect differences in segmentation are observed when these abilities first emerge at around $\circ ; 8$. We suggest that differences in the relative reliance on prosodic and TP cues might explain the differences in performance observed across these two populations. Third, cross-dialect segmentation appears to sometimes have a cost, and between the two dialects of French explored here, Canadian French-learning infants demonstrated greater flexibility in adapting to dialect variation in comparison to their Parisian French peers. Further research is needed to determine the cues accessible to infants exposed to each dialect and to identify differences in cue use and cue weighting that lead to dialect-specific patterns of segmentation across infants acquiring the same language in different linguistic communities.

\section{REFERENCES}

Best, C. T., Tyler, M. D., Gooding, T. N., Orlando, C. B. \& Quann, C. A. (2009). Development of phonological constancy: toddlers' perception of native- and Jamaicanaccented words. Psychological Science 20, 539-42.

Brent, M. R. \& Siskind, J. M. (2001). The role of exposure to isolated words in early vocabulary development. Cognition 81, B33-B44.

Butler, J., Floccia, C., Goslin, J. \& Panneton, R. (20I I). Infants' discrimination of familiar and unfamiliar accents in speech. Infancy I6, 392-4I 7.

Curtin, S., Mintz, T. H. \& Christiansen, M. H. (2005). Stress changes the representational landscape: evidence from word segmentation. Cognition 96, 233-62.

Fernald, A. \& Simon, T. (1984). Expanded intonation contours in mothers' speech to newborns. Developmental Psychology 2o, го4-г 3.

Gonzalez Gomez, N. \& Nazzi, T. (in press). Effects of prior phonotactic knowledge on infant word segmentation: the case of non-adjacent dependencies. Fournal of Speech, Language, and Hearing Research.

Gout, A., (200I). Etapes précoces de l'acquisition du lexique. Unpublished dissertation, Ecole des Hautes Etudes en Sciences Sociales, Paris, France.

Gout, A., Christophe, A. \& Morgan, J. L. (2004). Phonological phrase boundaries constrain lexical access II. Infant data. Fournal of Memory and Language 5I, 548-67.

Goyet, L., de Schonen, S. \& Nazzi, T. (2010). Syllables in word segmentation by French-learning infants: an ERP study. Brain Research 1332, 75-89.

Graf Estes, K., Evans, J. L., Alibali, M. W. \& Saffran, J. R. (2007). Can infants map meaning to newly segmented words? Statistical segmentation and word learning. Psychological Science 18, 254-60.

Höhle, B. \& Weissenborn, J. (2003). German-learning infants' ability to detect unstressed closed-class elements in continuous speech. Developmental Science 6, I 22-27.

Houston, D. M. \& Jusczyk, P. W. (2000). The role of talker-specific information in word segmentation by infants. Fournal of Experimental Psychology: Human Perception and Performance 26, I 570-82.

Houston, D. M. \& Jusczyk, P. W. (2003). Infants' long-term memory for the sound patterns of words and voices. Fournal of Experimental Psychology: Human Perception and Performance 29, I I $43-54$.

Houston, D. M., Jusczyk, P. W., Kuijpers, C., Coolen, R. \& Cutler, A. (2000). Crosslanguage word segmentation by 9-month-olds. Psychonomics Bulletin \& Review 7, 504-09. 
Johnson, E. K. \& Jusczyk, P. W. (200I). Word segmentation by 8-month-olds: when speech cues count more than statistics. Fournal of Memory and Language 44, I-20.

Johnson, E. K. \& Seidl, A. (2009). At I I months, prosody still outranks statistics. Developmental Science 12, I3 I-I4I.

Johnson, E. K. \& Tyler, M. (2010). Testing the limits of statistical learning for word segmentation. Developmental Science I3, 339-45.

Jusczyk, P. W. \& Aslin, R. N. (I995). Infants' detection of the sound patterns of words in fluent speech. Cognitive Psychology 29, I-23.

Jusczyk, P. W., Hohne, E. A. \& Bauman, A. (I999a). Infants' sensitivity to allophonic cues for word segmentation. Perception \& Psychophysics 62, 1465-76.

Jusczyk, P. W., Houston, D. M., \& Newsome, M. (I999b). The beginnings of word segmentation in English-learning infants. Cognitive Psychology 39, I 59-207.

Kooijman, V., Hagoort, P. \& Cutler, A. (2005). Electrophysiological evidence for prelinguistic infants' word recognition in continuous speech. Cognitive Brain Research 24, го9-16.

Kooijman, V., Hagoort, P., Cutler, A. (2009). Prosodic structure in early word segmentation: ERP evidence from Dutch ten-month-olds. Infancy 6, 59 I-6I 2.

Marquis, A. \& Shi, R. (2008). Segmentation of verb forms in preverbal infants. Fournal of the Acoustical Society of America I23, ELio5-ELi io.

Mattys, S. \& Jusczyk, P. W. (200ra). Phonotactic cues for segmentation of fluent speech by infants. Cognition $\mathbf{7 8}, 9 \mathrm{I}-\mathrm{I} 2 \mathrm{I}$.

Mattys, S. \& Jusczyk, P. W. (200Ib). Do infants segment words or recurring contiguous patterns? Fournal of Experimental Psychology: Human Perception and Performance 27, $644-55$.

Mattys, S., Jusczyk, P. W., Luce, P. A. \& Morgan, J. L. (r999). Phonotactic and prosodic effects on word segmentation in infants. Cognitive Psychology 38, 465-94.

Menard, L., Ouellon, C. \& Dolbec, J. (I 999). Prosodic markers of regional group membership: the case of the French of Quebec versus France. In J. Ohala (ed.), Proceedings of the XIVth International Congress of Phonetic Sciences, vol. 2, I60I-04. San Francisco: University of California.

Mersad, K. \& Nazzi, T. (2012). When Mommy comes to the rescue of statistics: infants combine top-down and bottom-up cues to segment speech. Language Learning and Development 8, 303-15.

Nazzi, T., Dilley, L. C., Jusczyk, A. M., Shattuck-Hufnagel, S. \& Jusczyk, P. W. (2005). English-learning infants' segmentation of verbs from fluent speech. Language and Speech 48, 279-98.

Nazzi, T., Iakimova, I., Bertoncini, J., Frédonie, S. \& Alcantara, C. (2006). Early segmentation of fluent speech by infants acquiring French: emerging evidence for crosslinguistic differences. Fournal of Memory and Language 54, 283-99.

Nazzi, T., Jusczyk, P. W. \& Johnson, E. K. (2000). Language discrimination by English learning 5-month-olds: effects of rhythm and familiarity. Fournal of Memory and Language 43, I-I 9 .

Newman, R., Bernstein Ratner, N., Jusczyk, A. M., Jusczyk, P. W. \& Dow, K. A. (2006). Infants' early ability to segment the conversational speech signal predicts later language development: a retrospective analysis. Developmental Psychology 42, 643-55.

Papousek, M., Papousek, H. \& Haekel, M. (I987). Didactic adjustments in fathers' and mothers' speech to their 3-month-old infants. Fournal of Psycholinguistic Research 16, 49I-5 I6.

Pelucchi, B., Hay, J. F. \& Saffran, J. R. (2009). Statistical learning in a natural language by 8-month-old infants. Child Development 8o, 674-685.

Picard, M. (1987). An Introduction to the comparative phonetics of English and French in North America. Amsterdam and Philadelphia: John Benjamins.

Polka, L. \& Sundara, M. (20I2). Word segmentation in monolingual infants acquiring Canadian English and Canadian French: native language, cross-dialect, and crosslanguage comparisons. Infancy $\mathbf{1 7}$, I98-232. 
Saffran, J. R., Aslin, R. N. \& Newport, E. L. (1996). Statistical learning by 8-month-old infants. Science 274, I $926-28$.

Schmale, R., Cristia, A., Seidl, A. \& Johnson, E. K. (2010). Developmental changes in infants' ability to cope with dialect variation in word recognition. Infancy $\mathbf{1 5}, 650-62$.

Seidl, A. \& Johnson, E. K. (2006). Infant word segmentation revisited: edge alignment facilitates target extraction. Developmental Science 9, 565-73.

Shi, R. \& Lepage, M. (2008). The effect of functional morphemes on word segmentation in preverbal infants. Developmental Science II, 407-1 3 .

Singh, L., Morgan, J. L. \& White, K. S. (2004). Preference and processing: the role of speech affect in early spoken word recognition. Fournal of Memory and Language 5I, I73-89.

Thiessen, E. D., Hill, E. A. \& Saffran, J. R. (2005). Infant-directed speech facilitates word segmentation. Infancy 7, 53-7I.

Thiessen, E. D. \& Saffran, J. R. (2003). When cues collide: use of stress and statistical cues to word boundaries by 7- to 9-month-old infants. Developmental Psychology 39, 706-I6.

van de Weijer, J. (I998). Language input for word discovery. Doctoral dissertation, University of Nijmegen (MPI Series in Psycholinguistics, 9).

van Heugten, M. \& Johnson, E. K. (2012). Infants exposed to fluent natural speech succeed at cross-gender word recognition. Fournal of Speech, Language, and Hearing Research 55, $554-60$. 